\title{
WHAT INDICATORS TO USE WHEN MEASURING SERVICES OF GENERAL INTEREST?
}

\author{
EDUARDA MARQUES DA COSTA \\ Centre for Geographical Studies \\ University of Lisbon \\ Alameda da Universidade, 1600-214, Lisbon, Portugal \\ eduarda.costa@campus.ul.pt \\ PEDRO PALMA \\ Centre for Geographical Studies \\ University of Lisbon \\ Alameda da Universidade, 1600-214, Lisbon, Portugal \\ p.palma@campus.ul.pt \\ DANIEL RAUHUT \\ Department for Social and Behavioural Studies \\ University West \\ Gustava Melins gata 2, 46186 Trollhättan, Sweden \\ daniel.rauhut@hv.se
}

\section{ALOIS HUMER}

Department of Geography and Regional Research

University of Vienna

Universitaetsstrasse 7/5, 1200 Vienna, Austria

alois.humer@univie.ac.at

\section{DANIELA CONSTANTIN}

Academy of Economic Studies of Bucharest

Bd. Lascar Catargiu 16 A, RO-010761 Bucharest, Romania

danielaconstantin_2005@yahoo.com

1 This paper is part of the applied research project Indicators and Perspectives for Services of General Interest in Territorial Cohesion and Development (SeGI), led by the Royal Institute of Technology (KTH), Sweden. It has been financed by the ESPON 2013 Programme and this financial support is gratefully acknowledged. Texts, maps and conclusions stemming from research projects under the ESPON programme presented in this report do not necessarily reflect the opinion of the ESPON Monitoring Committee. (C) ESPON, 2013. 


\author{
XABIER VELASCO ECHEVERRÍA \\ Territorial Observatory of Navarre \\ NASUVINSA \\ Avda. San Jorge, 8 bajo, Pamplona, Spain \\ xvelasce@nasuvinsa.es
}

\begin{abstract}
The services of general interest (SGI) have received increasing attention of the European Union, which considers them a key element of the European model of society. They not only play an important role in the ongoing competitiveness of the European economy, but are also essential for achieving the goal of promoting social and territorial cohesion. Their potential role in the pursuit of the objectives of European cohesion and convergence policies may be significant which calls for an appropriate measurement and analysis of territorial distribution. The indicators are assumed to be a key element in measuring and describing the SGI, however, it is necessary to make a serious reflection how such indicators should be selected. The selection of indicators can be conditioned by several factors, however, it is imperative to make a qualitative reflection on the adequacy and relevance of indicators to analyse the SGI. This reflection runs through the paper. The concept of indicators is addressed, and their strengths and weaknesses are discussed. The indicators are classified according to the role they play in the cause-effect relations in distinct territories. Three types of indicators are identified. Appraisal of indicators and review of literature render it possible to identify the most frequently used indicators and to see SGI analysis from several perspectives, thus verifying that indicators can present different meanings and relevance, based on a range of factors and the scale of analysis. Some of the uncertainties arising in the SGI territorial analysis, which can contribute to the success of the policy making process, are recognized through an example based on the ICT Telecommunication SGI sub-domain. Some procedures connected with the integration of different types of indicators are proposed in order to limit the emergent uncertainties resulting from their interpretation.
\end{abstract}

Keywords: Services of general interest, indicators, spatial cohesion, European Union.

\title{
INTRODUCTION
}

The current debate on SGI is characterised by the "lack of clarity on terminology" and by the fact that "concepts are used interchangeably and inaccurately" (CEC, 2011). In the Green Paper on Services of General Interest, the European Commission points out that different historical, economic, cultural and political development can lead to different terms and definitions across the Member States (CEC, 2003). Thus, the definition of SGI can vary from country to country and from region to region. The EC has made an attempt to standardise the concept of SGI across the Member States, and in the Green Paper has defined SGI as „,market and non-market services which the public authorities class as being of general interest and subject to specific public service obligations" (CEC, 2003).

The definition of the EC underlines a distinctive characteristic of SGI, namely the obligation to provide such services even in places where the level of demand is not sufficient to ensure that such services are efficient and cost-effective. Thus public authorities are obliged to provide SGI within certain parameters of quality, availability, accessibility and affordability, in order to ensure that such services are fully accessible to everyone.

The EU has, over time, devoted increasing attention to the issue of SGI since the provision of such services is considered a key element of the European model of society, being essential for the 
ongoing competitiveness of Europe's global industries, for the European economy more generally, and for the overall goal of promoting social and territorial cohesion (CEC, 2003). The adoption of the "Green Paper on Services of General Interest" can be seen as recognising the crucial importance of well-functioning, accessible, affordable and high-quality SGI for the quality of life of European citizens, the environment and the competitiveness of European enterprises (CEC, 2004).

In this context, the present paper has been elaborated under the ESPON project Indicators and Perspectives for Services of General Interest in Territorial Cohesion and Development (SeGI). The SeGI project aims to provide territorial evidence of the provision of services of general interest (SGI), identifying the existing gaps in order to support the implementation, monitoring and evaluation of territorial policy measures for SGI.

The use of indicators offers several advantages in terms of describing and analysing the provision of SGI across Europe. At the same time, however, it is important to use adequate indicators, based on their availability and the knowledge of their meaning. The available databases are commonly seen as insufficient or not adequate to support several studies at European regional and local scale. This frequent lack of data gives even more importance to this approach.

In the context of SeGI project, this paper is a reflexion on the role, meaning and adequacy of indicators in analysing the provision of SGI territorially, and it aims to provide an indicator framework that allows to measure SGI and to identify different territorial profiles. The paper is structured upon three main points.

The first one regards the definitions and concepts linked with indicators, including their strengths and weaknesses that are presented and discussed. A key element in this point is the discussion about the different roles and meanings that indicators can have.

The second main point presents an indicator appraisal and, through a literature review, different perspectives to analyse SGI are identified. We verify that indicators used and the structure of the analysis change according to the scale, the data availability, and the subject of analysis, showing that indicators can change their meanings and relevance in line with the different perspectives.

In the third point, an example of SGI territorial analysis is presented. Some of the problems that commonly arise from the indicators' interpretation are identified, and some solutions based on integrating different types of indicators are recommended.

\section{INDICATORS DEFINITION AND CONCEPTS}

Policy-making is a complex process integrating conceptual discussion and empirical experience, and is best supported by the identification of concrete and coherent information. Such information is commonly represented through the use of both quantitative and qualitative indicators.

Indicators are measures of synthesis offering the possibility to describe facts and then to simplify and measure them. Indicators are thus, par excellence, the way to communicate information of this type (Hoerning and Seasons 2004, in Marques Da Costa, 2011). Improving the level of communication between the general public and decision-makers, and contributing to general management functions and policy development are just some of the important roles played by indicators.

Indicators provide much more than just background information, they are "a piece of information which is part of a specific management process, and has been assigned significance beyond its face value" (Bakkes, J. et al, 1994). They have become indispensable tools, are well-established in a methodological sense and are widely used in many fields - from economics to ecology to health - and can be used at different levels, from the global scale to the neighbourhood one (Hammond et. al 1995). 
While the limitations and conditionings of their use are recognised, their utility is clearly evident in various scientific fields, including spatial planning and cohesion analysis.

Viewed as critical elements in the context of monitoring and evaluation, indicators are seen to be of growing importance for three main reasons:

- the need to understand and explain the main demographic, economic, environmental and socio-cultural changes, involving aspects such as population ageing, the restructuring of productive systems, the development of social networks or the preservation of natural resources;

- the need to discuss multi-sectional and multi-scale issues and concepts such as sustainability, competitiveness, territorial cohesion and social equity;

- and the need to strengthen the information structures in order to support the various actors and the governance system in the negotiation and decision process (Marques da Costa, 2011).

Getting indicators to analyse the cause-effect relations of territorial changes can be useful to understand how the information should be organised. One of the main steps towards the identification of a suitable indicator is to distinguish the different meanings and roles that indicators can play according to the different steps of territorial changes and policy implementation, identified in Figure 1.

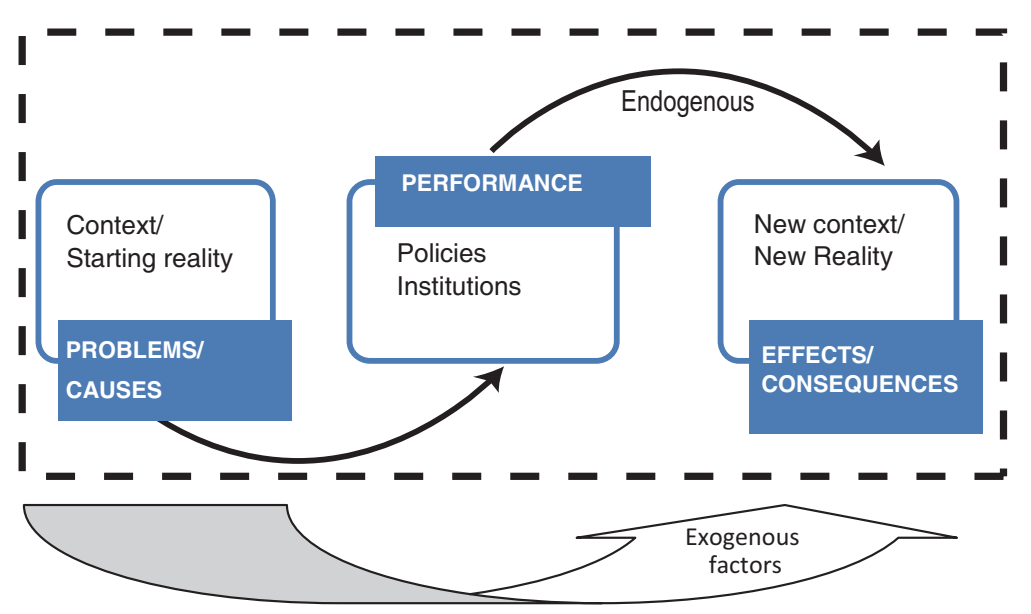

Figure 1. Cause-effect relations in the contextual changes of territories

Considering all the cause-effect relations we can define several types of indicators in accordance with their role in the territorial transformations.

Linked with the first stage, the "Context Indicators" allow deeming a situation in a starting period of analysis. They are mostly variables or indices of characterization of the territory in different domains. This includes indicators related to SGI context but also more general indicators in demographic, economic, social and institutional topics.

The second group of indicators is related to policy implementation and the policy's performance in territories. This second group of indicators allows the measurement of a degree to which a goal was achieved in the policy implementation process, with relation to policy objectives. We are talking about indicators that represent investment efforts (like the share of GDP in health system) or performance in SGI domains (as number of beds/1,000 inhabitants). 
The third group corresponds to "effect or result" indicators. They should represent the "effect" of a policy implementation. For example the increasing share of students at a given education level could represent the result of a policy effort.

These are the naturally used indicators when analysing the SGI but are these enough to present a coherent and solid territorial analysis of SGI? What could be the relevance of considering the other two types of indicators?

\section{THE ROLE AND RELEVANCE OF "CONTEXT INDICATORS" AND THEIR CONNECTION TO "SGI INDICATORS"}

Identifying the territorial gaps and disparities in the provision of SGI in the EU context represents a significant challenge. Many factors need to be taken into account in this discussion and the context indicators can play an important role in it.

As an example of contextual conditions we highlight the different political-administrative organisation models that exist across the Member States. These differences are reflected in the propensity towards a more centralised or decentralised system of governance. Moreover, differences in the organisation of systems between central-regional and central-regional-local powers, evidently have a significant effect on the process of service provision. This is particularly evident as shown by social SGI in the education and health sectors, which display vastly differing levels of performance in countries like Portugal, France and Germany. This means that contextual analysis should include systems of governance in parallel with SGI indicators provision.

The relationship between the pattern of SGI provision and territorial demographic and economic dynamics is another factor that must always be considered. The territorial dynamics and characteristics such as the level of urbanisation, the demographic structure linked to the ageing process, the infrastructure development and other regional development signs can introduce important shifts in the provision of SGI.

The demographic and urban structures determine the way in which SGI are developed (affecting levels of demand and efficiency) and, in addition, are a vital factor in adjusting the SGI provision to regional settings. Ageing areas tend to have poorer levels of service provision. Moreover, it is clear that having a poor pattern of service provision does not help to attract additional population elements into a region. Densely urbanised areas tend, on the other hand, to have a wider set of accessible services, but they often suffer from a lack of effectiveness or simply from a lack of quality. This is particularly due to the fact that these regions attract a growing number of users.

This analysis highlights the importance of integrating contextual indicators into the broader analysis of indicators in the context of SGI. In what follows some contextual indicators are mentioned (Table 1). 
Table 1. Integrating context indicators into the SGI regional differentiation analysis

\begin{tabular}{|l|l|}
\hline GDP/capita & Natural population change 2000 - 2007 \\
\hline Employment rate & Population aged 65+ in 2005 \\
\hline Unemployment & Population aged 14- in 2005 \\
\hline Depopulation trends & Youth dependency ratio in 2005 \\
\hline Population density & Old age dependency ratio in 2005 \\
\hline Typology of ageing and depopulation & $\begin{array}{l}\text { Urban-rural typology, based on population density, } \\
\text { FUA ranking and land cover }\end{array}$ \\
\hline Direct indicator of depopulation & Typology of Functional Urban Areas (FUAs) \\
\hline Ageing trend & Regional destination attractiveness for 2005-2010 \\
\hline Population Change 2000-2007 & Areas assigned to potential urban strategic horizon \\
\hline Change in Population 2005-2050 - Scenarios & Urban population \\
\hline
\end{tabular}

Source: Marques da Costa, E., Palma, P., Rauhut, D., Humer, A., Constantin, D., Velasco, X., 2012, pp. 13.

In both examples the context indicators are useful since they allow to distinguish the different realities that can represent different conditions to provide SGI.

\section{THE ROLE AND RELEVANCE OF "EFFECT OR RESULT INDICATORS"}

Besides the previous ones, there is a third group: the "effect or result indicators". As stated before, these are mainly related to measuring the SGI effects. In order to correctly characterise the services, as well as produce a good analysis and evaluation of their effects, it is essential to understand the role and the meaning of the indicators used. Before discussing the analysis process more fully, however, we seek to highlight the cause-effect relationship that must first be taken into account.

In the Green Paper on Services of General Interest (CEC, 2003), as well in the following documents (e.g. CEC, 2004), the evaluation of services is one of the key elements under consideration. As noted in CEC (2003), "the evaluation of services of general interest is important because of the significance of these services for the economy as a whole and for everyone's quality life" (pp. 28). This evaluation has three fronts:

- "The regular evaluations of network industries that have been liberalised" (sectional evaluation);

- Cross-sectional (horizontal evaluation);

- Consumer satisfaction surveys.

With regards to sectors and horizontal evaluations, the processes of analysis and the availability of data are not systematic, making it impossible to integrate this kind of indicators into the evaluation system. There is no data available on sectional and horizontal indicators by region or for a homogeneous period, thus invalidating their inclusion in the indicator analysis.

The last front, as suggested in a CEC document (2003), is associated with Eurobarometer opinion and qualitative surveys, from which some data and indicators could be used. In order to show the relevance and the role of these types of indicators an example is presented (Figure 2). The example presented here is related with a specific domain of SGI, more associated with the health care services. 


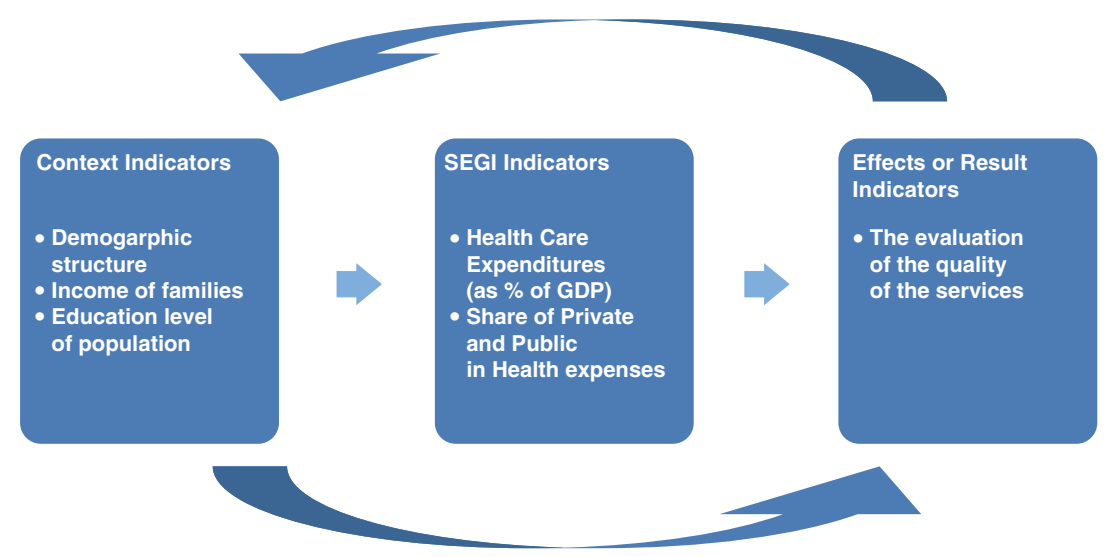

Figure 2. Cause-effect relations in relation to SGI - example

Source: RAUHUT, D., BORGES, L. et al (2011), pp 22.

The indicator "Health Care Expenditures as a \% of GDP" corresponds to an SGI indicator, while the effect can be appraised by an indicator evaluating the quality of the health service. Other common indicators used to evaluate the effects are those that allow us to evaluate the accessibility and availability of the services, for example the level of user satisfaction, as such indicators correspond to the results of the investment, represented by the available infrastructures and personnel related to the sector.

In some cases, however, it is not so easy to establish this indicator sequence (Context, SGI and Effects/Results). They can often be much more complex than the example presented here, being at the same time SGI indicators and effects indicators, depending on the point of view or the context. The "\% of Households with broadband access" is an SGI indicator but at the same time it is also an effect/result indicator when seen as a result of the cost of the service or, more generally, the shape of national policies to provide the infrastructure.

In general terms, and considering all the types of indicators presented here, the relativity of scale should also be taken into account in the comparative analyses since it affects the relevance of indicators. Individual SGI are quite different in nature, depending on whether they are administered from the parish, municipal, regional or national level, depending on having relevant indicators. For example in parish level, pre-school or elderly care issues are significantly important and the availability of services generally depends on the level of population need.

Therefore, besides the distinction of indicators based on the role they play, they must be distinguished by levels and in accordance with the type of issue and its scale. If some indicators are more appropriate for global or national issues, others are more relevant to the local level. Indicators must be analysed at different levels, depending on the roles and responsibilities of government in managing these issues as well as the prevailing degree of the decentralisation of powers and functions in any given situation.

In the next point, an indicator review based on two methodological elements will be presented, and some of the issues previously covered will underpin this analysis, mainly the relativity of scale and the availability of data. Besides presenting a review of indicator's relevance and adequacy to analyse the SGI territorial disparities, a literature review allows to identify different perspectives of analysis. 


\section{INDICATORS APPRAISAL AND PERSPECTIVES OF ANALYSIS}

In order to comprehend the regional differentiation in the provision of SGI and to evaluate its effect, at different scales and in the social cohesion process, a discussion and a review of the most frequently used indicators is made in the following analysis. In addition to the indicators, the approach, or the structure of analysis, also plays an important role.

To deal with these two issues, two methodological steps are made. The first one consists in an inventory of available indicators which are then classified according to their relevance and adequacy to analyse the regional disparities in the SGI provision across European regions. The second step is supported in a literature review that gives an important contribution to the identification of the most commonly used indicators but, more than that, allows to recognize and to understand the diversity of perspectives in analysing SGI.

First of all, it is important to establish a framework for all the arrangements, schemes and functions, often covering a rather broad and often heterogeneous field that can be considered under the rubric of SGI. In accordance with the political-normative definition in EU treaties and communications, two main domains are distinguished: social services of general interest (SSGI) and services of general economic interest (SGEI). The SSGI domain contains four sub-domains, namely: labour market, education, care services and social housing. SGEI in turn covers two sub-domains, the infrastructure (e.g. energy, transportation) and ICT Telecommunication (eg. communication infrastructure).The following analyses are thus performed according to the sub-domains set.

\section{THE NEED TO DISCUSS AND REVIEW THE RELEVANCE AND ADEQUACY OF SGI INDICATORS}

The inventory of indicators available in Eurostat has given us access to a large, but rather disperse, set of information. It has been possible to find indicators linked to the previously pointed six sub-domains of SGI: some indicators are associated with employment in SGI services, others are related to the availability (expressed in numbers) of infrastructure and equipment, and still others are linked to the quality of services. Nevertheless, the large number of indicators is significantly shortened after the analysis of information availability and scale of analysis.

Another aspect that we must take into account is the disparity between domains: the lack of indicators in respect of social housing or the ICT domain contrasts with the availability in the domains of health or infrastructure and equipment, namely infrastructure of accessibility by road, motorway and train, as well as in the environment domain, for example water and waste management. In addition, the available information on SGI in relation to the labour market domain is also quite limited.

The ability of each indicator to effectively measure SGI service provision or its effect on the cohesion process should also be kept in mind when indicator lists are presented.

A classification of indicators was made, in order to further contribute to this discussion, based on their relevance, to analyse the provision of SGI. The indicators were scored in accordance with 3 criteria: very relevant - position 1; medium relevance - position 2; lowest relevance - position 3 . This task was undertaken by six team members with the final allotted value being the average value for all assessments, thus reducing the influence of individual subjectivity. Realizing if indicators are relevant to measure SGI or understanding the effect of the SGI in matter of social and territorial cohesion, is not so obvious, especially because we are working with heterogeneous types of services, some specifically linked to the economy, while others primarily related to social and population services. Besides their classification into economic or social domain, the question of how to measure 
and analyse territorial effects and territorial cohesion, is also important here. This is another area where the discussion on the use of indicators could and should be improved.

In this context, in parallel with the overview/classification of statistical indicators, an empirical study (literature review and political documents) review was undertaken. This helped to develop a range of rather more qualitative ways in which to discuss the relevance and utility of indicators. In order to carry out the literature review a database of scientific papers where various SGI were analysed was created. The main objective has been to understand which indicators are commonly used by the scientific community, but also to collect other information that may prove useful in relation to the SGI analysis.

38 documents were analysed in total. They were spread across the six SGI sub-domains and were taken from various European contexts. In Table 2, we can see the number of articles by theme and we can note here that several themes were covered. The numbers presented clearly illustrate the importance of sub-domains like infrastructure or services with an economic basis, like telecommunications, labour market assistance systems, energy, postal services, and transport.

Table 2. Main themes analysed in the readings

\begin{tabular}{|l|c|l|c|}
\hline \multicolumn{1}{|c|}{ Theme } & $\begin{array}{c}\text { Number } \\
\text { of } \\
\text { articles }\end{array}$ & \multicolumn{1}{|c|}{ Theme } & $\begin{array}{c}\text { Number } \\
\text { of } \\
\text { articles }\end{array}$ \\
\hline $\begin{array}{l}\text { Telecommunications (infrastructures, } \\
\text { accessibility and/or services provided) }\end{array}$ & 15 & Postal Services & 2 \\
\hline Labour Market social costs and assistance) & 9 & Social equity & 2 \\
\hline Energy & 8 & Demographic trends and elderly services & 2 \\
\hline $\begin{array}{l}\text { Transport infrastructures and services } \\
\text { (road, rail) }\end{array}$ & 8 & Monetary and fiscal policies/Exports & 2 \\
\hline Child care & 4 & $\begin{array}{l}\text { Public administration and Public/social } \\
\text { spending }\end{array}$ & 2 \\
\hline Services in general & 4 & Water/Waste & 2 \\
\hline Social housing & 4 & Monetary and fiscal policies/Exports & 2 \\
\hline Education level & 3 & Public administration and social spending & 2 \\
\hline Financial services & 2 & $\begin{array}{l}\text { Environmental protection and growth } \\
\text { (understood as water supply/collection of } \\
\text { waste and air pollution) }\end{array}$ & 1 \\
\hline Health Care Services & 2 & Long-term care & 1 \\
\hline Housing & 2 & & 2 \\
\hline
\end{tabular}

Source: Marques Costa, E., Marques Costa, N., Palma, P. et al. (2011), pp. 13.

From this process there emerges a list of indicators commonly used to study each sub-domain of SGI. By comparing the two lists (the statistical one from Eurostat systems and the literature review one) we are able to generate a more accurate picture of which indicators could be useful in understanding and measuring the potential regional differentiation and influence, in terms of SGI, in respect of territorial and social cohesion. Besides these indications, we can also generate some important information about data availability and sources.

An example of the output generated based on these two lists is provided in Table 3. As a result of the score relevance exercise, some indicators stand out as displaying high levels of relevance. 
This suggests that they have produced a greater level of consensus among the team members and are more commonly cited in the literature review. Such examples could be found in the social housing, education and care services domains; however, they are selected from different perspectives at the regional scale, namely: number, population served, and costs.

Themes like social housing, care services or child care services are very prominent in the literature review, and the indicators referred to here are thus considered to have a high importance value. Nevertheless, these indicators are not available in Eurostat to NUTS II or III, which means that the data can only be found at national or even municipal-level sources. Frequently, indicators considered in the literature review are more detailed.

Table 3. Comparing Official Statistical Indicators list and the Readings Indicators list: Some examples

\begin{tabular}{|c|c|c|}
\hline \multicolumn{2}{|l|}{ Official Sources } & \multirow[b]{2}{*}{ Readings/literature review } \\
\hline & $\begin{array}{l}\text { More detailed } \\
\text { available } \\
\text { Geographical } \\
\text { Unit }\end{array}$ & \\
\hline Social Housing & & Social Housing \\
\hline $\begin{array}{l}\text { Social Protection Expenditure: Tables by } \\
\text { benefits }\end{array}$ & NUTS 0 & $\begin{array}{l}\text { Social benefits for the function: Housing } \\
\text { (as a } \% \text { of GDP) }\end{array}$ \\
\hline $\begin{array}{l}\text { Distribution of population by tenure status, } \\
\text { type of household and income group (Source: } \\
\text { SILC) (ilc_lvho02) - Tenant - reduced price or } \\
\text { free }\end{array}$ & NUTS 0 & $\begin{array}{l}\text { The no. of low-cost private rental dwell- } \\
\text { ings; Tenants }\end{array}$ \\
\hline HICP - housing (teicp040) & NUTS 0 & $\begin{array}{l}\text { Median house prices; Housing afford- } \\
\text { ability indicator I (house price to income } \\
\text { ratio) }\end{array}$ \\
\hline $\begin{array}{l}\text { Dwellings by type of ownership, type of } \\
\text { building and total occupants and total number } \\
\text { of persons }\end{array}$ & NUTS 0 & Home ownership \\
\hline Care Services & & Care Services \\
\hline Health care expenditure by financing agent & NUTS 0 & $\begin{array}{l}\text { Long-term care receipts and expendi- } \\
\text { tures; Public health expenditure as \% of } \\
\text { total health expenditure }\end{array}$ \\
\hline $\begin{array}{l}\text { Social Protection Expenditure: Tables by } \\
\text { benefits }\end{array}$ & NUTS 0 & $\begin{array}{l}\text { Child care expenditures; Sickness leave; } \\
\text { Disability leave }\end{array}$ \\
\hline Hospital beds (HP.1) by region, unit and facility & NUTS 2 & $\begin{array}{l}\text { Number of hospital beds per } 100000 \\
\text { inhabitants }\end{array}$ \\
\hline $\begin{array}{l}\text { Consultation of a medical doctor during the } \\
\text { past } 12 \text { months by sex, age and activity status } \\
(\%)\end{array}$ & NUTS 0 & Visits to a doctor in the last year \\
\hline Labour Market & & Labour Market \\
\hline Employment by economic activity & NUTS 2 & Overall employment rate \\
\hline Unemployment by sex and age & NUTS 3 & Overall unemployment rate \\
\hline Long-term (12 months and more) & NUTS 2 & Long-term unemployment rate \\
\hline
\end{tabular}




\begin{tabular}{|c|c|c|}
\hline \multicolumn{2}{|l|}{ Official Sources } & \multirow[b]{2}{*}{ Readings/literature review } \\
\hline & $\begin{array}{c}\text { More detailed } \\
\text { available } \\
\text { Geographical } \\
\text { Unit }\end{array}$ & \\
\hline Infrastructures & & Infrastructures \\
\hline $\begin{array}{l}\text { Population connected to public water supply } \\
\text { (NUTS } 2 \text { ) - in } \%\end{array}$ & NUTS 2 & Access to water \\
\hline Infrastructure - electricity - annual data & NUTS 0 & Capacity of electricity networks \\
\hline $\begin{array}{l}\text { Electricity - marker prices - half-yearly prices } \\
\text { - Data until } 2007\end{array}$ & NUTS 0 & Energy (electricity and gas) - Price trends \\
\hline $\begin{array}{l}\text { Railway transport - Annual national and inter- } \\
\text { national railway passenger transport by region } \\
\text { of embarkation and region of disembarkation }\end{array}$ & NUTS 2 & Number of rail passengers by kilometres \\
\hline Modal split of passenger transport & NUTS 0 & $\begin{array}{l}\text { Share of number of rail passengers by } \\
\text { kilometres in relation to other transports }\end{array}$ \\
\hline $\begin{array}{l}\text { General government expenditure by function } \\
\text { (COFOG) }\end{array}$ & NUTS 0 & Public funds spent in this industry \\
\hline ICT Telecom & & ICT Telecom \\
\hline $\begin{array}{l}\text { Information technology expenditure in millions } \\
\text { of euro and as a percentage of GDP }\end{array}$ & NUTS 0 & Public funds spent in this industry \\
\hline $\begin{array}{l}\text { Mobile phone subscriptions (per } 100 \text { inhabit- } \\
\text { ants) (tin00060) }\end{array}$ & NUTS 0 & $\begin{array}{l}\text { Mobile cellular subscribers per } 100 \\
\text { inhabitants }\end{array}$ \\
\hline $\begin{array}{l}\text { Households with broadband access } \\
\text { (isoc_r_broad_h) }\end{array}$ & NUTS 2 & $\begin{array}{l}\text { Broadband Internet subscribers per } 100 \\
\text { inhabitants }\end{array}$ \\
\hline $\begin{array}{l}\text { Percentage change of value added by ICT sector } \\
\text { at current prices }\end{array}$ & NUTS 0 & $\begin{array}{l}\text { Value added in the ICT sector (as a } \\
\text { percentage of total business sector value } \\
\text { added) }\end{array}$ \\
\hline Education & & Education \\
\hline $\begin{array}{l}\text { Population } 15 \text { years and older by highest level } \\
\text { of education attained }\end{array}$ & NUTS 2 & Level of education in the Nordic regions \\
\hline $\begin{array}{l}\text { Number of students by level of education, } \\
\text { orientation, sex and region }\end{array}$ & NUTS 2 & Share of female students \\
\hline $\begin{array}{l}\text { Pupils and Students in all levels of education } \\
\text { (ISCED 0-6) - as \% of total population at } \\
\text { regional level }\end{array}$ & NUTS 2 & Students per inhabitant ratios $(\%)$ \\
\hline
\end{tabular}

Source: Marques da Costa, E., Palma, P., Rauhut, D., Humer, A., Constantin, D., Velasco, X., 2012, pp. 8.

The infrastructure domain is the one most frequently mentioned here, probably because it aggregates a wide number of services, and the indicators highlight the supply and economic perspective of the SGI. In this sense, indicators linked to road, rail and air transport (length of lines, number of airports), oil, gas, electricity, and water infrastructures as well as postal and communications services, come in three different categories: length, costs and employment. The first two are perhaps more interesting. The first is related to service availability but also to the level of accessibility to services, while the second is linked more to the political administrative system and to the affordability of a given service. 
The utility of indicators for our purpose depends on data availability. Numerous potential indicators exist, but many are only available at NUTS 0 or I. As such, they cannot be used effectively to analyse regional differentiation or to understand the effect on territorial and social cohesion. This is particularly problematic in the infrastructure domain.

\section{NEW PERSPECTIVES IN THE ANALYSIS OF SGI}

The methodological process encompassing the indicator checks and the literature review delivered some important results in terms of the problems highlighted and the kind of perspectives used to analyse different sub-domains. We can thus see that the various approaches are all rather interesting and can, when taken together, deliver a more complete understanding of SGI. A more common approach comes from the Fourth Report on Economic and Social Cohesion and is shown in Table 4. It is a fully descriptive approach, attempting to cover multiple domains.

Table 4. SGI domains and indicators from the Fourth Cohesion Report-example 1

\section{Transportation infrastructure:}

Rate of use, density and length of motorways

Rate of use, density and length of railway lines

Volume of air traffic

Accessibility to flights

Volume of sea/river transport

Regional accessibility and connectivity to means of transport

\section{Energy}

Final energy consumption

Share of oil in energy consumption

Capacity of electricity networks

\section{Telecommunications}

Access to high capacity networks

Potential of households and businesses in urban and rural areas to access broadband

\section{Health services}

Accessibility to health services

Provision of health centres

Beds per 1,000 inhabitants

\section{Environmental protection and growth (understood as water supply/collection of waste and air pollution)}

Access to water

Water treatment/pollution

Waste generation

Source: CCE (2007) in Marques Costa, E., Marques Costa, N., Palma, P. et al. (2011), pp. 14.

In this perspective, three main dimensions are considered when analysing the sub-domains of SGI: the use (eg. rates of use, energy consumption), the availability (eg. beds per inhabitant, density of motorways) and the accessibility (eg. Access to high capacity networks, accessibility to health services). 
Other approaches tend to be linked to just one or two dimensions: relating to accessibility, and focusing on the various meanings of accessibility behind the term 'physical accessibility'. Social inequality and affordability are also fundamental to the cohesion process. In this case some indicators related to prices of the provision, or indicators reflecting purchasing power of the population can be very relevant. As we already noted in the conceptualisation of SGI, the continuity and quality of services are crucial in the analysis of SGI, particularly in rural areas (Table 5).

Table 5. SGI domains and indicators from Project Report: Contribution of Services of General Interest to Economic, Social and Territorial Cohesion - example 2

\section{Universality and General Accessibility}

1. Percentage of persons not having access to the service (current situation and recent trends)

2. Main characteristics of persons not having access to the service (current situation and recent trends)

3. Rate of use of the services (current situation and recent trends)

4. Main characteristics of persons not using the services (current situation and recent trends)

5. Number of service providers for any user (current situation and recent trends)

6. Other

\section{$\underline{\text { Affordability and Price Equalisation }}$}

1. Affordability indices

2. Price trends

3. Other

\section{$\underline{\text { Social Accessibility }}$}

1. ercentage of specific categories of persons (elderly persons, handicapped or disabled persons, large families, ...) not having access to the services (current situation and recent trends)

2. Price differentiation with respect to specific categories of persons (current situation and recent trends)

3. Specialised equipment for handicapped persons and other specific categories of persons (current situation and recent trends)

4. Other

\section{Territorial Accessibility}

1. Percentage of the territory not having access to the service (current situation and recent trends)

2. Main characteristics of those parts of the territory not having access to the service (current situation and recent trends)

3. Spatial density of networks by type of equipment (per inhabitant and per square km) (current situation and recent trends)

4. Price differentiation with respect to location (current situation and recent trends)

5. Other

\section{Continuity and Quality Of Provision}

1. Reliability of services: interruptions of services, delays, repair time, ...

2. Security of supply, safety

3. Time for connection to the network / to the service

4. System and time to respond to complaints

5. Other, with particular reference to consumer perception of services offered

\section{Spatial Cohesion and Development}

1. Spatial imbalances

2. Description of bottleneck situations

3. Other

Source: Bauby (2004) in Marques Costa, E., Marques Costa, N., Palma, P. et al. (2011), pp. 15. 
Some documents are not so descriptive, however. Instead, such documents seek to provide a rather more in-depth thematic analysis, often referring to dimensions that reinforce a long-term planning perspective (Table 6). One such example is the ageing process and the increasing social disparities that characterise European regions, which forces us to think about long term strategies in some domains, such as child care, in order to promote labour force activity and social cohesion. One such approach bases the study on indicators like: employment rates for mothers with children under 3 years of age; access rates for children under 3 years to licensed ECEC services; employment in child care services and the level of education associated with such services; and payment levels for trained staff in child care facilities.

Table 6. Domains and main problems from Study on Social and Health Services of General Interest in the European Union - example 3

\section{Long term services:}

Increasing interest is now, in many countries, being shown in tackling the problems associated with gaps in services, with improving the quality of services and with adequately preparing for future and ongoing demographic change. Gaps have clearly emerged in terms of service provision in this area. The territory is not fully covered, services are often very limited, and the level of care provided in the home is very restricted in terms of the number of hours. In some cases it's not provided by the state but rather by associations, other organisations or by companies. This study suggests that these services are still significantly underdeveloped in many countries and that one's ability to access them can vary substantially depending on where one lives.

\section{Child care:}

In most of the Member States the EU-Barcelona targets (providing child care by 2010 to at least $33 \%$ of children under 3 years of age and to at least $90 \%$ of children between 3 years of age and the mandatory school age) are far from being reached, in particular for the younger age group. Given the diversification of child care services and the fragmentation of responsibilities, a problem in respect of a lack of coherence and of poor governance procedures has clearly arisen. Specifically quality control procedures are more difficult to implement given the increasing number of independent childminders and 'for-profit' providers. Child care services for those up to three years of age are quite limited in all of the four countries referred to, especially in rural areas. In all four countries, alternatives to collective crèches, e.g. childminders, family crèches, etc., usually have no nationwide supply and are often relatively expensive.

In general terms, choice and flexibility in respect of the services provided do not always meet the expectations of the users as both public and private supply have developed on a traditional pattern of collective childcare, with conventional, rather rigid opening hours demanding a continuous, generally full-time attendance.

\section{Social housing:}

Social housing organisations are facing greater demands in those cases where they retain a predominant role with a view to fulfilling this mission, and in cases where there is a weak social housing sector (e.g. Hungary, the Czech Republic, Spain, etc.), discussions are however currently ongoing between the government, social and academic actors to establish such a sector. The lack of standardised definitions of social housing across the EU - and the resulting absence of common methods and cycles of data collection in all Member States - makes it difficult to establish meaningful comparisons, given the disparity in terms of indicators, methods and cycles of data collection.

Source: Huber, M., Maucher, M., Sak, B., (2006) in Marques Costa, E., Marques Costa, N., Palma, P. et al. (2011), pp. 16.

In the context of child care services we can also find work that has been done in relation to an analysis of the competent public authorities, examining the organisation of services, the 'market' share of such services, and the governance mode. Some indicators, such as service provision expenditures and service provision by form of intervention, are used here. 
The labour market domain is the second most frequently mentioned in the 'state of art' compilation. Its relationship with SGI emerges, primarily, in the context of cohesion policy and social transfers. Another relevant theme here is 'Labour markets and public welfare', which clearly highlights the importance of more general indicators like the financial situation, demographic trends, monetary and fiscal policies, export ratios, and education levels.

The fourth approach is more centred on the provider's and consumer's perspective. It is more obviously related with the use and availability of services, but also with affordability, and primarily appears in relation to communications, energy and infrastructure requirements (Table 7).

Table 7. Domains and Indicators from The diffusion of ICT in OECD countries - example 4

\section{ICT infrastructure and access: \\ Fixed telephone lines per 100 inhabitants \\ Television sets per 100 inhabitants}

\section{Access to, and use of ICT by households and individuals:}

Proportion of households with a radio

Frequency of individual access to the Internet in the last 12 months (from any location): (a) at least once a day; (b) at least once a week but not every day; (c) at least once a month but not every week; and (d) less than once a month.

Proportion of households with electricity

\section{Use of ICT by businesses:}

Proportion of businesses using computers

Proportion of businesses with an extranet

\section{ICT sector and trade in ICT goods:}

Proportion of total business sector workforce involved in the ICT sector

Value added in the ICT sector (as a percentage of total business sector value added)

Source: Pilat \& Devlin (2004) in Marques Costa, E., Marques Costa, N., Palma, P. et al. (2011), pp. 16.

Some indicators are used to analyse the availability of or, in some sense, the accessibility to services, like the number of fixed telephone lines per 100 inhabitants or the proportion of households with electricity. In other way, other indicators allow to measure the use of services such as the frequency of individual access to the internet or the proportion of businesses using computers.

With the literature review analysis it was possible to distinguish several perspectives used to analyse the SGI. Depending on the research objectives and on the researcher himself, the relevance and the adequacy of indicators can change. If a long-term planning perspective is adopted, it is important, for example, to perform a horizontal analysis of indicators, instead of, for example, using some indicators linked with utilization rates. It is possible that the same indicator may not be adequate and relevant to study the same sub-domain if the perspective of analysis adopted is different.

In the last part of the paper a practical example of SGI territorial analysis based on indicators is shown. This exercise does not attempt to point out the most suitable indicators that can be used; instead, it tries to show some of the main problems that arise in the SGI territorial analysis and how these can be solved, through combining the three types of indicators, in order to better support the policy making process. 


\section{TERRITORIAL ANALYSIS OF SGI - INTEGRATING ICT INDICATORS ANALYSIS}

When using indicators in a territorial analysis of SGI it is important to be aware of their limitations. Several factors that have already been mentioned can transform the indicators into useless instruments and be harmful for the policy making process. The data availability gaps, the relativity of scale issues, the lack of meaning, relevance and adequacy of indicators, the nature of indicators, and the perspectives of analysis are factors of huge relevance for a reliable analysis of SGI. The challenge is to consider all these factors throughout the process of territorial analysis, and even knowing that it is impossible to achieve a perfect situation, it is essential to minimize the mistakes and the uncertainties that arise during the process.

The example shown below intends to identify problems that commonly arise in this kind of analysis and to present certain good practices that can be followed to provide better and more reliable information to the decision makers. For this purpose, the SGI sub-domain of ICT Telecommunication is the research subject.

The statistical data regarding this sub-domain present significant gaps. The ICT and related technologies are not uniformly spread around the world, and in some regions this recent trend can contribute to a certain shortage of data. There are a few indicators available, and some of them have several gaps, both in territorial and time perspective. From the previous exercises of literature review and indicators appraisal it is possible to identify that one of the most widely used indicators to analyse the ICT sub-domain is Households with broadband access (Figure 3). As we will see, the meaning and utility of this indicator is very doubtful and vulnerable to some factors.

One of the aspects that contribute to the weakness of its meaning is the technological progress inherent to ICT sub-domain. The constant innovation and progress can change the meaning of indicators that were once considered useful and appropriate. The increase of free and universal access to the Internet, through wireless connections or hotspots, allows the access to internet in various places and by various means. If in the workplaces and homes often there is the possibility to access internet, the actual trend is the sprawling of internet access points in different places like cafes or bars, public spaces such as green areas, malls or even on public transport.

In this context, does the indicator Households with broadband access traduce now the reality of 10 years ago? Nowadays, the computer is also no longer the only means through which one can access the internet. It is increasingly common to use other means to access the internet, as in the case of Tablet or Smartphone. All these innovations have contributed to a situation in which internet access is not confined to a fixed connection at home, making it difficult to render the real dimension of the provision and consumption of this service through the presented indicator.

However, at least in the present context, we expect a strong correlation between the internet access and the percentage of households with broadband access. In the case of countries with less developed ICT sector, the indicator may also describe a situation close to reality, since the ways to access internet still the traditional ones, related with fixed connections. On the other hand, the indicator may reveal a situation undersized in the most ICT developed countries, like the Nordic countries. 


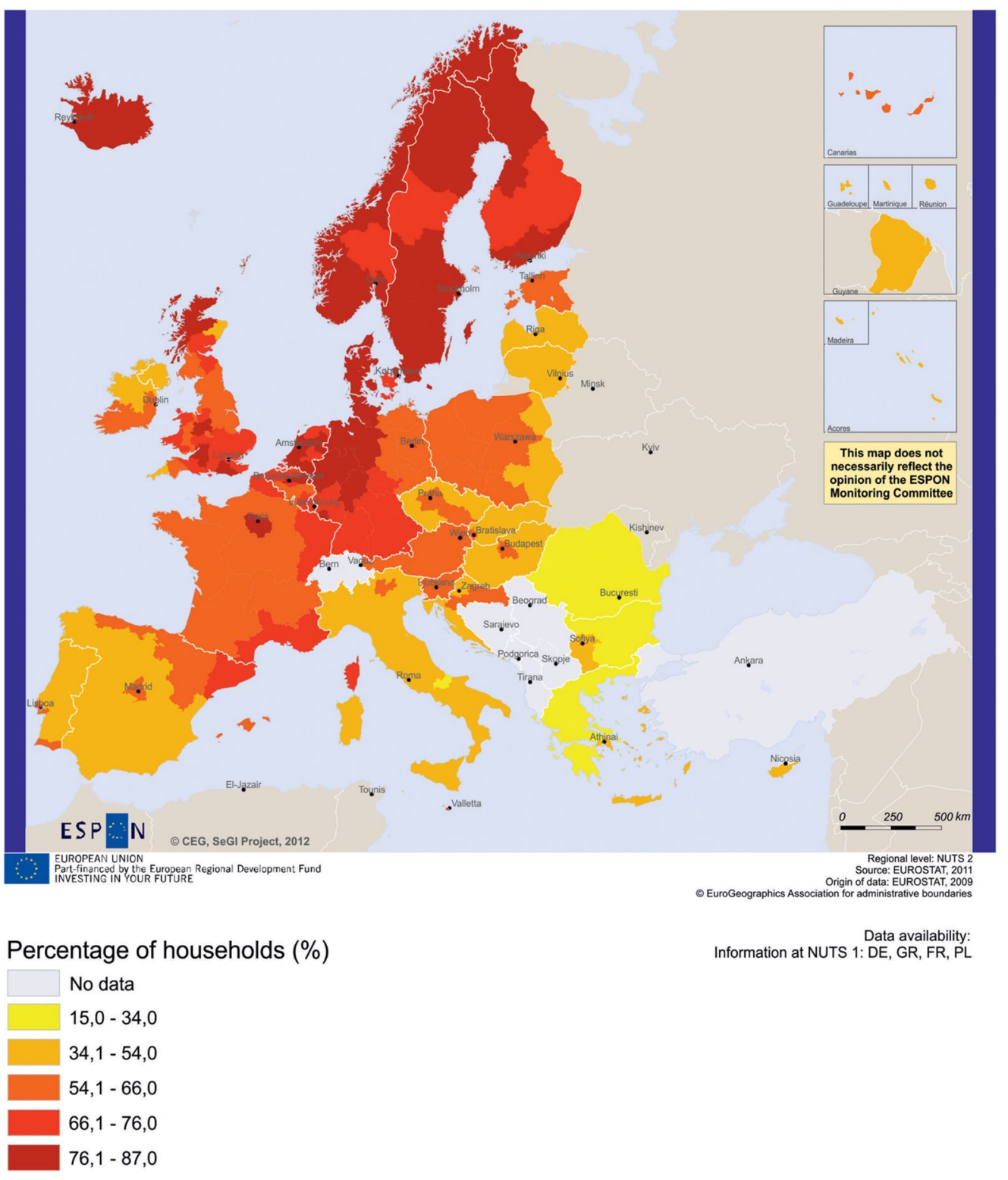

Figure 3. Households with broadband access, 2009.

Source: Marques da Costa, E., Palma, P., Rauhut, D., Humer, A., Constantin, D., Velasco, X., 2012, pp. 18.

This is a very common situation that can significantly bias the construction of policies and thus, these policies will have undesired practical effects. Following the previous discussion on the relevance of other types of indicators, we consider it extremely important to combine the previous indicator, an SGI indicator, with some context indicators and, if possible, also with effect indicators. One context indicator that can help us to understand the patterns identified trough the Households with broadband access indicator, could be the indicator of Individuals that never used a computer (Figure 4). 


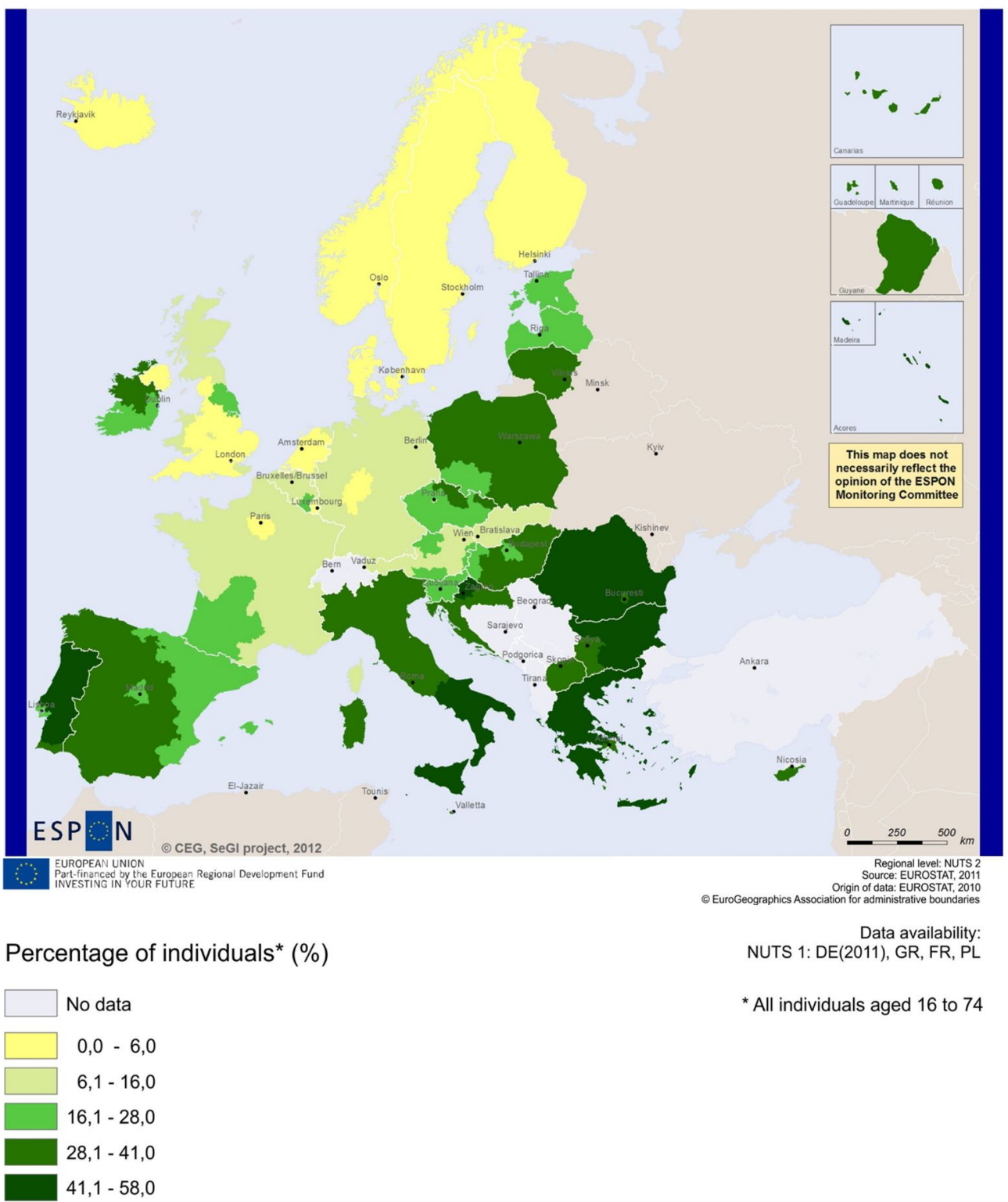

Figure 4. Individuals (16-74 years old) who have never used a computer, 2009.

Source: Marques da Costa, E., Palma, P., Rauhut, D., Humer, A., Constantin, D., Velasco, X., 2012, pp. 18.

Comparing the two indicators and respective maps shows that the regions with smaller percentage of households with access to broadband are the regions with the highest percentages of people who have never used a computer. Examples of this situation are the countries of Eastern Europe and in general terms, the Mediterranean countries. On the contrary stand out the Nordic countries with higher rates of computer use and higher rates of broadband coverage. 


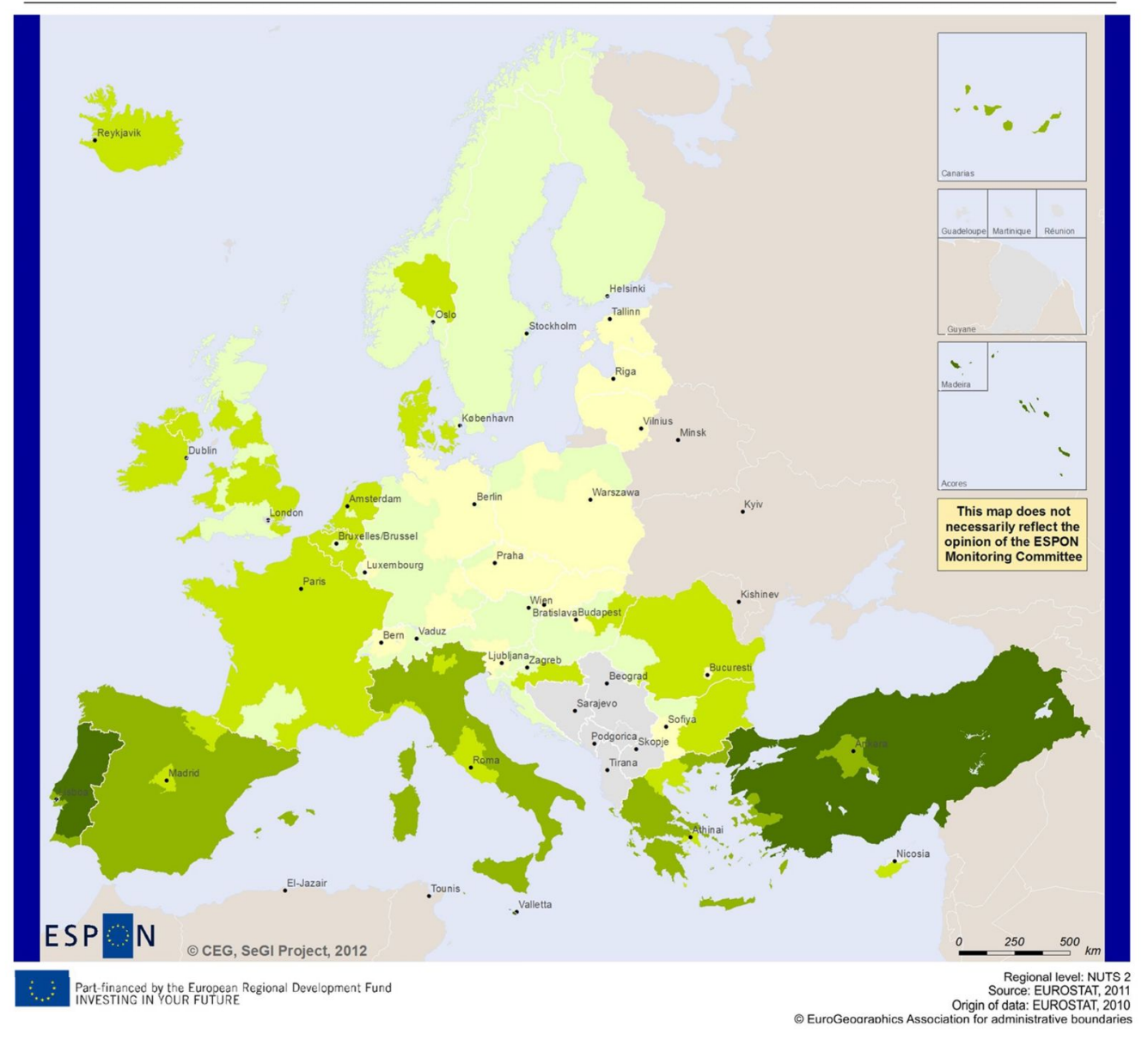

\section{Percentage of individuals* $(\%)$}

* All individuals aged 25 to 64

No data

$$
3,3-14
$$

$14,1-23$

$23,1-39$

$39,1-65$

$65,1-81,9$

Figure 5. Individuals aged 25-64 with lower secondary education attainment, 2010.

Source: Marques da Costa, E., Palma, P., Rauhut, D., Humer, A., Constantin, D., Velasco, X., 2012.

In a similar approach, and considering a context indicator related to education - People aged 25-64 with lower secondary attainment (Figure 5), it is also possible to identify an evident pattern. The countries of Southern Europe are those with the highest rates of people who completed compulsory education but not continued their education in higher levels of education. These are also the countries/ regions that were already identified as having the lowest coverage in broadband access. 
With the isolated analysis of the Households with broadband access indicator it was possible to identify in a clear way the regions and countries with the most significant gaps concerning the provision of this specific service. Looking exclusively to this indicator the decision makers would create a group of incentives to reduce these perceived gaps, for example, by investing more in the construction of ICT infrastructures. However, the indicator has, by itself, several weaknesses that can affect the success of the resulting policies. Considering the other two indicators, it is possible to better understand the patterns identified and verify that some of the low values are closely related to regions where the population level of education, interests and habits are not optimal or do not present the traditional characteristics of a highly developed ICT society.

More than a matter of existing gaps in the provision of service, it is a matter related to the demand. The lack of ability/need/interest of the population to access the internet can negatively affect the levels of service provision and thus, the aims of the policies must be distinct, and lead with the demand instead of focus on the offer.

Following the integrative approach shown before it is also important to combine some effect indicators, such as consumer opinions regarding the effectiveness and quality of the provision of service, but in this specific case the available data does not allow to do it.

It is obvious that this analysis could be much more complex, and more indicators considered, but we consider that this example already highlights some important aspects that must be taken into account when the objective is to identify existing SGI provision gaps in order to support the implementation, as well as monitor and evaluate the territorial policy measures for SGI.

\section{CONCLUDING REMARKS}

The policy making process and the related monitoring and evaluation processes require information, which is represented by indicators. This information must be organised in an up-to-date system, and it must be harmonised for each sector and according different territories of analysis. In this particular case, the search for territorial evidence of the provision of services of general interest is highly dependent on the indicators that are used. Indicators are measures that enable a simplification of reality and entail a number of advantages, which makes them a fundamental tool for a wide range of topics. This ability to simplify reality promotes a set of issues that deserve special attention as they could put into question the usefulness and the real relevance of the indicators. It is undeniable that the usefulness and value of indicators are essential to support various processes; however, it is necessary to ensure a critical view on their meaning and be aware of their limitations.

The data availability gaps, the relativity of scale issues, the lack of meaning, and the perspectives of analysis are just some of the factors that can change the relevance and meaning of the indicators, and thus make the difference between a reliable or unreliable analysis of SGI. The challenge is to consider all these factors along the process of territorial analysis. Moreover, knowing that it is impossible to achieve a perfect situation, it is essential to minimize uncertainties that arise from data analysis.

The findings of this paper suggest that there is a need to integrate the SGI indicators with context indicators as the area of SGI is multifaceted and heterogeneous. Territorial evidence identified at the outset, with the analysis of a single indicator, is often illusory, which becomes noticeable only after other indicators of different nature have been examined.

Another conclusion is related to the need to measure SGI effects. In fact, this process is difficult not only due to the scarcity of relevant data, but also because effects should be evaluated in different 
dimensions (in direct way - related to frequency, accessibility and quality of services, in indirect way - the contribution to social and territorial cohesion). The SGI effects analysis obliges to undertake an inter-sectorial analysis.

A third big conclusion is related to the need to improve reflexion about the concepts and indicators to measure SGI provision: availability, accessibility, quality, equity, efficiency. The findings of literature review highlight the gaps in some services (aspects related to availability or quality) and the need to adjust it for an ongoing ageing population process and to rural and depopulated areas (namely thinking on accessibility, equity and efficiency). Context indicators as complementary to SGI indicators have become relevant for better understanding of reality.

Beyond all the limitations identified in this paper, indicators are needed to provide better knowledge.

\section{REFERENCES}

Bakkes J., van de Born G.J., Helder J.C., Swart R.J., Hope C.W., Parker J.D.E., 1994. An Overview of Environmental Indicators: State of the art and perspectives. UNEP Environment Assessment Technical Report 94-01, 82 pp.

Bauby P., Hall D., Bernard T., Sak B., 2004. Contribution of Services of General Interest to Economic, Social and Territorial Cohesion. CIRIEC Project - Final Overall Report, Liege. http://www.ciriec.ulg.ac.be/fr/telechargements/RESEARCH_REPORTS/2004_ciriecdgregio_sgei.pdf [1 April 2013].

Briggs D., Corvalan C., Nurminen M., 1996. Linkage Methods for Environment and Health Analysis. Geneva, WHO library, $153 \mathrm{pp}$.

CEC, 2003. Green paper on Services on general interest. Commission of the European. Communities COM, 270 final, Brussels. http://eur-lex.europa.eu/LexUriServ/LexUriServ. do?uri=COM:2003:0270:FIN:PT:PDF [1 April 2013].

CEC, 2004. White Paper on Services of General Interest, Commission of the European Communities COM (2004) 374 final, Brussels. http://eur-lex.europa.eu/LexUriServ/site/en/com/2004/ com2004_0374en01.pdf [1 April 2013].

CEC, 2007. Growing regions, growing Europe. Fourth report on economic and social cohesion. Commission of the European communities, COM, 273 final, Brussels. http://ec.europa.eu/regional_policy/sources/docoffic/official/reports/cohesion4/pdf/4cr_en.pdf[1 April 2013].

CEC, 2011. A Quality Framework for Services of General Interest in Europe. COM (2011) 900 final, Brussels.

Hammond, A., et al., 1995. Environmental Indicators: A Systematic Approach to Measuring and, Reporting on Environmental Policy Performance in the Context of Sustainable Development, World Resources Institute. http://pdf.wri.org/environmentalindicators_bw.pdf [1 April 2013].

Huber M., Maucher M., Sak B., 2006. Study on Social and Health Services of General Interest in the European Union. Final Synthesis Report. Ciriec. http://www.socialeconomy.eu.org/spip. php?article691 [1 April 2013].

Marques da Costa, E., 2011. Monitoring and Evaluation of Policies - Methodological Contribution based on the Portuguese Study [in:] D. Farinos (ed.) From Strategic Environmental Assessment to Territorial Impact Assessment: reflection about evaluation process. PUV: Universitat de Valência, 309-330 pp. 
Marques da Costa E., Palma P., Rauhut D., Humer A., Constantin D., Velasco, X., 2012. Indicators of Services of General Interest in EU regional context: between the need to measure and the lacking of their meaning. 52nd Annual Congress of the European Regional Science Association International, Regions in Motion, Bratislava, Slovak Republic, 21-25 August 2012.

Marques da Costa E., Marques da Costa N., Palma P. et al., 2011. SeGI, Indicators and perspectives for services of general interest in territorial cohesion and development. Appendix 4-Indicators Appraisal. Applied Research 2013/1/16. Interim Report version 14/10/2011. ESPON \& Royal Institute of Technology.

Marques Da Costa E., Marques Da Costa N., Palma P., Abreu D., 2012. Indicator appraisal and review [in:] Rauhut, D., Borges, L. (eds.) SeGI, Indicators and perspectives for services of general interest in territorial cohesion and development. Applied Research 2013/1/16, Draft Scientific Report, Version 18/10/2012, Annexes 8-9 to SeGI Scientific Report, ESPON \& Royal Institute of Technology, pp. 5-120.

Pilat D., Devlin A., 2004. The diffusion of ICT in OECD countries, [in:] OECD (2004). The economic impact of ICT: measurement, evidence and implications, OECD, pp. 19-36.

Szyszczak E., Davies J., Andenaes M., Bekkedal T., 2011. Developments in Services of General Interest. T.M.C. Asser Press, 266 p.

Rauhut D., Borges L. (eds.), 2011. SeGI, Indicators and perspectives for services of general interest in territorial cohesion and development. Applied Research 2013/1/16. Interim Report version 14/10/2011. ESPON \& Royal Institute of Technology.

Wallea V., 2008. What Services are Public? What Aspects of Performance are to be Ranked? The Case of "Services of General Interest. International Public Management Journal, 11(3), p. 256-274. 